KLECKNER, N. (1996): Meiosis: How could it work? Proc Natl Acad Sci USA 93: 8167-8174.

Mashkina, O. S., L. M. Burdaeva, M. M. Belozerova and L. N. VyunOva (1989): Method of obtaining diploid pollen of woody species. Lesovedenie 1: 19-25.

MoK, D. W. and S. J. PeloQUIN (1975): Three mechanisms of $2 n$ pollen formation in diploid potatoes. Can J Genet Cytol 17: 217-225.

PfEiffer, T. W. and E. T. Bingham (1983): Abnormal meiosis in alfalfa, Medicago sativa: cytology of $2 n$ egg and $4 \mathrm{n}$ pollen formation. Can J Genet Cytol 25: 107-112.

RAe, A. M., N. R. Street and M. Rodríguez-Acosta (2007): Populus trees, pp. 1-28. In: Genome mapping and molecular breeding in plants, vol. 7, Forest trees, edited by C. KolE, Springer-Verlag, Berlin, Heidelberg.

RAMANNA, M. S. (1974): The origin of unreduced microspores due to aberrant cytokinesis in the meiocytes of potato and its genetic significance. Euphytica 23: 20-30.

RAMANNA, M. S. (1979): A re-examination of the mechanisms of $2 n$ gamete formation in potato and its implications for breeding. Euphytica 28: 537-561.

RAmsey, J. and D. W. Schemske (1998): Pathways, mechanisms, and rates of polyploidy formation in flowering plants. Annu Rev Ecol Syst 29: 467-501.

RAY, M. and M. K. TOKACH (1992): Cytology of $2 n$ pollen formation in diploid crested wheatgrass, Agropyron cristatum. Crop Sci 32: 1361-1365.
RheE, S. Y. and C. R. Somerville (1998): Tetrad pollen formation in quartet mutants of Arabidopsis thaliana is associated with persistence of pectic polysaccharides of the pollen mother cell wall. Plant J 15(1): 79-88.

SCHOPFER, C. and P. HEPLER (1991): Distribution of Membranes and the Cytoskeleton During Cell Plate Formation in Pollen Mother Cells of Tradescantia. J Cell Sci 100: 717-728.

Shamina, N. V., E. I. Gordeeva, N. M. Kovaleva, E. G. Seriukova and N. V. Dorogova (2007): Formation and function of phragmoplast during successive cytokinesis stages in higher plant meiosis. Cell Biol Int 31: 1-10.

SHELDON, J. M. and H. G. DiCKINSON (1986): Pollen wall formation in Lilium: The effect of chaotropic agents, and the organisation of the microtubular cytoskeleton during pattern development. Planta 168: 11-23.

Smith, E. C. (1943): A study of cytology and speciation in the genus Populus L. J Arnold Arbor, Harvard University 24(3): 275-305.

TAKANA, I. (1991): Microtubule-determined plastid distribution during microsporogenesis in Lilium longiflorum. J Cell Sci 99: 21-31.

WANG, J., X. Y. KANG, D. L. LI, Y. C. JING and Z. H. ZHANG (2006): Meiosis and chromosome behavior of pollen mother cell in Populus simonii Carr. $x$ P. nigra $L$. 'Tongliao'. Acta Bot Boreal-Occident Sin 26(11): 2231-2238.

\title{
A Novel Gel-based Method for Isolation of Stigmas During Controlled Pollination Experiments
}

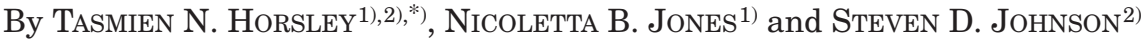

(Received 22 th August 2008)

\begin{abstract}
In forestry, controlled pollination (CP) allows the combining of genetic material of selected elite trees to produce high quality, and consequently high value, seed. The aim of the present study was to develop a novel isolation method that would allow the technique to be conducted without expensive and time-consuming bagging, making CPs on small-flowered eucalypts commercially viable. We compared the current method of isolating

\footnotetext{
1) Shaw Research Centre, Sappi Forests, Howick, South Africa.

2) School of Biological and Conservation Sciences, University of KwaZulu-Natal, Scottsville, South Africa.

*) Corresponding author: TASMIEN N. Horsley. Tel: (+2733) 3302455; Fax: (+2733) 3304938 E-Mail: tasmien.horsley@ sappi.com
}

inflorescences using exclusion bags to a novel method which uses sodium alginate gel. Sodium alginate was effective in keeping external pollen away from the stigma, since no seed was produced in those treatments that were not manually pollinated but isolated in this way. In addition, flowers hand-pollinated and isolated with sodium alginate produced progeny that were $100 \%$ outcrossed with the applied pollen. The exclusion bags, on the other hand, were not as effective in protecting the stigma as seed was produced in those treatments that were isolated with an exclusion bag without being handpollinated. Sodium alginate isolation also increased the efficiency of control-pollinations as the gel was naturally shed, removing the need for operators to return to the tree to remove the isolation material.

Key words: control-pollination, bud isolation, sodium alginate, exclusion bag, Eucalyptus, Artificially Induced Protogyny. 


\section{Introduction}

Most flowering plants rely on pollinators to deposit compatible pollen onto stigmas for ovule fertilisation and seed set (RAMSEY and VAUGHTON, 2000). However, pollen quantity may be limiting if pollinators are rare, or if plants compete for the services of pollinators (Groom, 1998). Pollen quality may also be limiting, despite adequate pollination, if pollinators deposit selfor incompatible pollen onto stigmas, or deposit closelyrelated pollen which may lead to early-acting inbreeding depression lowering seed set (Pound et al., 2003). These limitations of natural pollination can largely be overcome with controlled pollination (CP), which allows the quality and quantity of pollen deposited on the stigma to be optimised. In one study, CPs resulted in increased survival, size and reproduction of the plants in subsequent years (LEHTILA and SyRJANEN, 1995). In forestry, the technique has been used to improve seed yields, control the level of outcrossing in seed orchards, improve breeding through knowledge of both female and male parents, achieve interspecific hybridisation, and study self-incompatibility levels (HARBARD et al., 1999; MoNCUR, 1995).

For Eucalyptus, the first-developed CP-method, termed the Conventional method, took advantage of the natural protandry (where pollen is released before the stigma becomes receptive) of the eucalypt flower (VAN WYK, 1977). The technique involved three flower visits (emasculation and bagging, subsequent pollination of receptive stigmas and re-bagging, removal of bags), and was consequently very time consuming. A more efficient cross-pollination method was later developed, originally for E. globulus, requiring only one visit to the flower (emasculation and immediate pollination of stigmas cut to induce receptivity, followed by bagging) and consequently named One Stop Pollination (OSP; HARBARD et al., 1999). However, although OSP has been used with some success on a range of eucalypt species (HARBARD et al., 2000; BARBOUR and SPENCER, 2000), small-flowered species have displayed unacceptably low seed set (WILLIAMs et al., 1999).
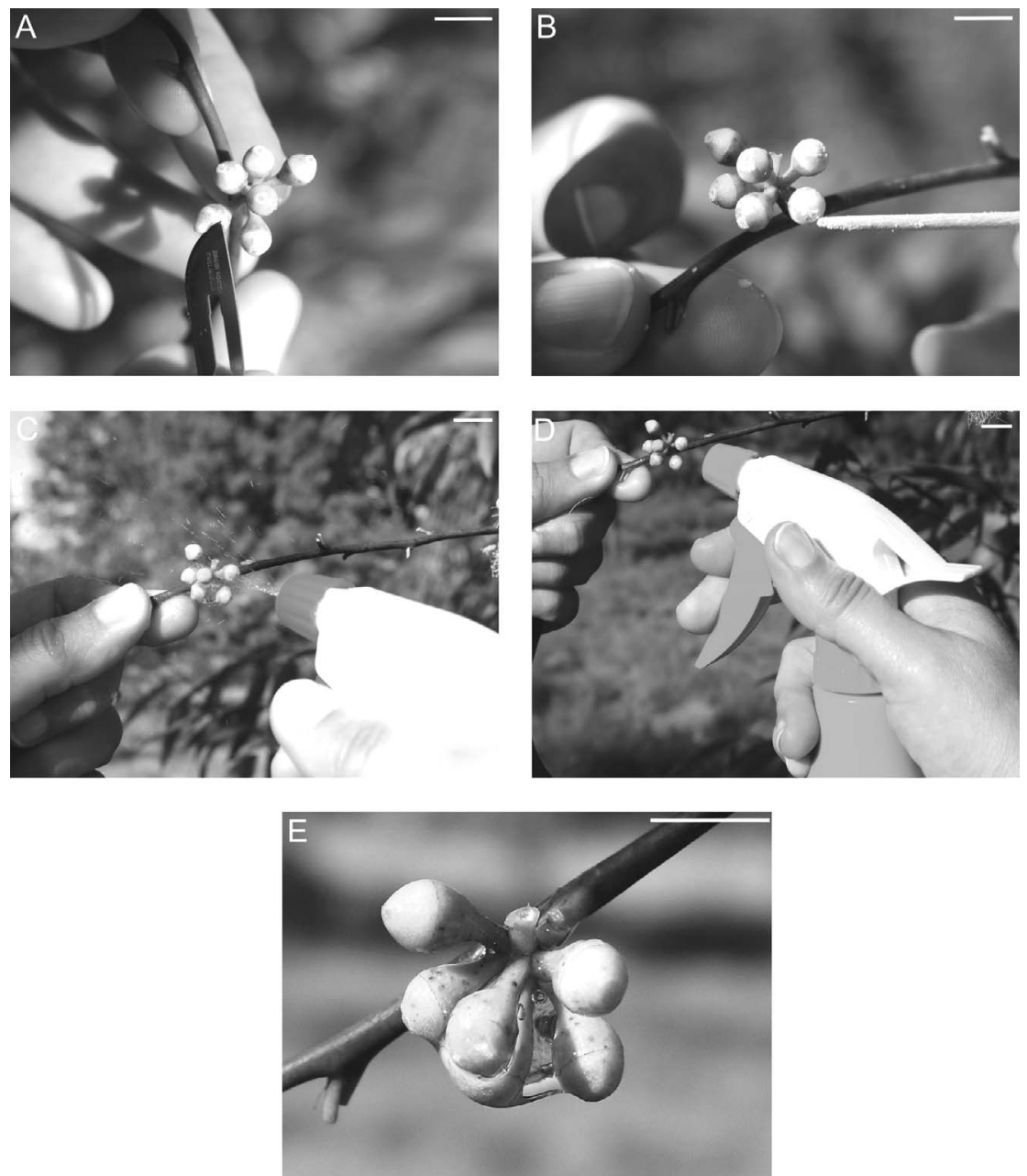

Figure 1. - Sodium alginate isolation of AIP-pollinated Eucalyptus grandis buds. (a) A horizontal cut was made through the top quarter of a ripe flower bud without removing the operculum, (b) pollen was applied directly to the cut surface; (c) pollinated buds were sprayed with $100 \mathrm{mM}$ calcium nitrate solution for $5 \mathrm{sec}$; (d) buds were then immediately sprayed with $2.2 \%$ sodium alginate solution for 5 sec; (e) a protective gel formed around pollinated buds. Bars $=1 \mathrm{~cm}$. 
Artificially Induced Protogyny (AIP; Assis et al., 2005) is a relatively new technique for the controlled pollination of eucalypt trees. It involves cutting off the tip of the operculum of the mature flower bud just prior to anthesis (release of pollen from anthers), with the cut positioned so as to remove the stigma and expose the cut surface of the upper style to which the target pollen is applied, without emasculation or isolation of flowers (Figure $1 A$ and $B$ ). A recent study has, however, identified the need for self- and external-pollen exclusion in order for the AIP technique to be effective under field conditions (HORSLEY et al., 2008).

Effective flower isolation is highly desirable during controlled pollinations, since it can enhance the accuracy of breeding through full pedigree control (DUTKOWSKI et al., 2006). The main sources of pollen contamination during eucalypt CPs are foreign pollen from nearby trees and self pollen transferred geitonogamously from other flowers within the canopy of the tree (SNOw et al., 1996). Self-pollination within a eucalypt flower is generally prohibited by the protandrous nature of the flower (ELDRIDGE et al., 1993). To prevent unwanted pollen transfer during controlled pollinations, flowers must be physically isolated, with the method of isolation dependant on the flower characteristics, sexual compatibility between genotypes, pollen quantity and viability, and mode of pollen dissemination (SUNDSTROM et al., 2002).

For Eucalyptus pollinations, bagging is the simplest method of isolation and involves covering the flowers with breathable material, such as a nappy-liner, paper bag, glassine or fine cloth (MoNCUR, 1995). Individual styles may also be isolated with a small piece of plastic tubing, sealed at one end (HARBARD et al., 1999). After fertilisation, the stigma abscises taking the tube with it. Use of this method allows all available flowers to be pollinated, unlike bag isolation where flowers that are preor post-anthesis, and likely to be enclosed in the bag, must be removed to prevent contamination (WILLIAMS et al., 1999). The plastic-tube isolation method is, however, restricted to large-flowered eucalypt species, such as $E$. globulus, which have single flowers. In small multiflowered inflorescences, such as in $E$. grandis, it becomes expensive and logistically difficult to isolate individual flowers in this way (BARBOUR, 1997; HARBARD et al., 2000).

Isolation efforts may need to be increased depending on the type of pollinations being carried out (BRADFORD, 2006). For example, with interspecific or hybrid crosses, in which contamination can be readily observed in the progeny (phenotypic observations), isolation is not imperative. However, when controlled pollinations are performed intraspecifically, it is important that a reliable isolation method be employed since contaminants are not as easily phenotypically observed and the more expensive route of molecular marker analysis may have to be employed.

The aim of the present study was to develop a practical isolation method for application when using the AIP technique to perform controlled pollinations on smallflowered eucalypts.

\section{Material and Methods}

\section{Plant material used in study}

The experiments were conducted on mature trees located in two separate clonal (grafted) orchards planted at the Sappi, Shaw Research Centre in KwaZulu-Natal, South Africa. Both orchards were situated at $29^{\circ} 29^{\prime} \mathrm{S}$, $30^{\circ} 11^{\prime} \mathrm{E}$ at $1100 \mathrm{~m}$ above sea level. Eucalyptus grandis was the study species in which intraspecific crosses were performed. The breeding population for this species was made up of open-pollinated families from selections made in land-races in South Africa and from provenances in the natural range in Australia.

Maternal genotypes included in the study were B0133 (in orchard 1), T1099 and T1144 (in orchard 2). Paternal genotypes included T1074, B0133 and T1087. Pollinations in orchard 1 were carried out during peak flowering (approximately $80 \%$ of genotypes flowering in the orchard), while those in orchard 2 took place at the end of the flowering season (approximately 20\% of genotypes flowering in the orchard). Trees were chosen on the basis of floral abundance and accessibility for handpollinations, leading to one ramet from each genotype being pollinated. To take into account different micro-climates, replications were evenly distributed around each tree (viz. north, south, east and west).

\section{Pollen collection and processing}

For pollen extraction, branches containing ripe flower buds were collected and kept in $100 \mathrm{ml}$ bottles containing water to prevent drying out of the branch. To ensure that there was no contamination from other pollen, all open flowers were removed from the branches before placing in the laboratory overnight. The following morning, when the opercula of unopened flowers had shed and the filaments unfolded, the anthers were excised and left in a desiccator in the presence of silica gel to dry for approximately $48 \mathrm{~h}$ at room temperature. When the relative humidity $(\mathrm{RH})$ in the desiccator had reached $10 \%$, the dried anthers were sieved through a 30 micron mesh to remove debris. The resulting pollen was placed into polypropylene vials, sealed in glass bottles containing silica gel and stored in a freezer at $-10^{\circ} \mathrm{C}$ until needed.

\section{In vitro pollen germination}

Pollen viability was tested under laboratory conditions before use in controlled pollinations. Pollen was left at room temperature and $\mathrm{RH}$ for 8 hours to rehydrate. In vitro germination was carried out using $30 \%(\mathrm{w} / \mathrm{v})$ sucrose, supplemented with $0.15 \mathrm{mg} \mathrm{l}^{-1}$ boric acid in a liquid medium (Horsley et al., 2007). Pollen from each genotype was placed into glass vials containing the in vitro medium (three replications per genotype) and left to incubate in a germination chamber in a completely randomised design for 48 hours at $29^{\circ} \mathrm{C}$. After the required time period had elapsed, $5 \mu$ l was transferred from the test-tube to a glass slide. Percent germination was scored using a light microscope (x100 magnification) to count the number of pollen grains germinated out of a total of 50 grains. Six glass slides per genotype (two slides per test tube) were scored for germination 
(sub-samples), giving a total of 300 pollen grains counted per treatment. Pollen was deemed to have germinated if the pollen tube length was greater than one-half of the diameter of the pollen grain (POTTS and MARSDENSMEDLEY, 1989).

\section{Controlled pollination}

Two controlled pollination experiments were performed, one in 2005 and the other in 2007, both employing the AIP method of controlled pollination (Assis et al., 2005). In the 2005 study, B0133 x T1074 crosses were carried out in orchard 1 to test the effect of sodium alginate on pollen tube growth (i.e. to see if sodium alginate would interfere with pollen germination and tube growth). A follow-up study was conducted in 2007 in orchard 2, where T1099 x B0133, T1099 x T1087, T1144 x B0133 and T1144 x T1087 crosses were performed. This was to confirm the 2005 results, as well as test an additional treatment, viz. sodium alginate isolation of non-pollinated buds, to determine if sodium alginate would be effective in keeping extraneous pollen away from the stigma. A secondary aim was to examine the effect of flowering intensity on open-pollinated (OP) seed production in order to determine whether CPs would increase quantity and quality of seed yields towards the end of the flowering season. Appendix A shows the number of flowers pollinated per treatment.

Artificially Induced Protogyny involved cutting off the tip of the operculum of a mature flower bud prior to anthesis to expose the cut surface of the upper style, to which the target pollen was applied, without emasculating the flower. Pollinated flowers were then treated to either nappy-liner isolation (also referred to as 'bagging'), sodium alginate isolation or non-isolation. During bagging, a nappy-liner (Quick-dry nappy-liners, manufactured by Unsgaard Packaging Ltd, South Africa) was placed over three umbels (maximum of 21 flowers) and secured at each end using twist wires. These bags were removed when the stigma had fully oxidised, which occurred two weeks after pollination. For sodium alginate isolation, pollinated buds were first sprayed with $100 \mathrm{mM}$ calcium nitrate solution for 5 seconds and then immediately sprayed with $2.2 \%$ sodium alginate solution for 5 seconds, allowing a gel to form around the buds (Figure 1). The sodium alginate gel was shed naturally upon operculum-fall. Open controls consisted of buds that had been neither artificially pollinated nor isolated and were included to give an indication of natural pollination success.
Seed set

All capsules remaining at maturity (10 months after pollination) were harvested and allowed to dry out in the laboratory and release their seed. The number of viable seeds in each capsule were counted. Seeds were considered viable if they were rounded, solid and dark in colour as opposed to flat and possessing a light-brown colour (Pound et al., 2002).

\section{Molecular marker analysis of pollen contamination}

Molecular marker analysis was performed on leaf samples from progeny of seed parents B0133 and T1144. DNA was extracted using the Qiagen DNeasy Plant Kit (QIAGEN, Valencia, CA, USA). The contamination rate of each of the treatments was determined using microsatellite markers (BRONDANI et al., 1998) to test for non-parental (contaminant) alleles in each progeny set. The number of individuals to be genotyped was determined by the lowest rate of contamination to be detected, namely $5 \%$, and thus 20 individuals per treatment were chosen for parentage analysis. Eight highly informative microsatellite markers (viz. EMBRA 37, EMBRA 45, EMBRA 48, EMBRA 56, EMBRA 94, EMBRA 98, EMBRA 219, EMBRA 227) were used to ensure adequate power to discriminate closely related pollen contaminants from pollen used in the CP trials.

\section{Statistical analysis}

SPSS Version 15.0 was used for all statistical analyses. Pollen viability and seed set per flower pollinated data were subjected to Analysis of Variance (ANOVA) and Duncan multiple range tests. Percentage pollen viability was angular transformed prior to the analysis.

\section{Results}

\section{In vitro pollen germination}

There were significant differences between pollen batches used in the controlled pollination experiments $(\mathrm{F}=11.492 ; \mathrm{P}=0.009)$. Genotype $\mathrm{T} 1087$ exhibited the highest in vitro pollen germination $(64.0 \pm 1.7 \%)$ and genotype T1074 the lowest $(38.7 \pm 6.1 \%$; Table 1$)$.

\section{Controlled pollinations}

In terms of seeds per flower pollinated, there were no significant differences $(\mathrm{F}=0.743 ; \mathrm{P}=0.596)$ between isolation treatments in genotype B0133 (Figure 2a). However, in genotype T1099, there were significant effects $(\mathrm{F}=3.872 ; \mathrm{P}=0.006)$, with exclusion bag isola-

Table 1. - In vitro germination of Eucalyptus grandis pollen used in controlled pollinations. Letters $(\mathrm{a})$ and $(\mathrm{b})$ indicate statistical significance $(\mathrm{P}<0.05)$, where treatments indicated by the same letter are not significantly different.

\begin{tabular}{llll}
\hline Species & Genotype & $\mathrm{N}$ & Mean \pm std error $(\%)$ \\
\hline E. grandis & $\mathrm{T} 1087$ & 3 & $64.0 \pm 1.7^{\mathrm{a}}$ \\
E. grandis & $\mathrm{B} 0133$ & 3 & $58.0 \pm 2.1^{\mathrm{a}}$ \\
E. grandis & $\mathrm{T} 1074$ & 3 & $38.7 \pm 6.1^{\mathrm{b}}$ \\
\hline
\end{tabular}


(a)

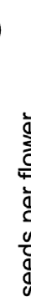

(b)

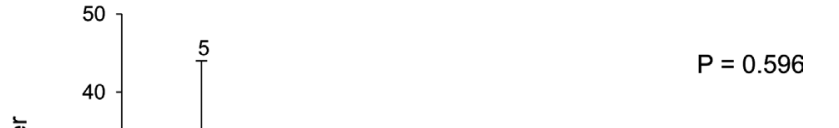

(c)

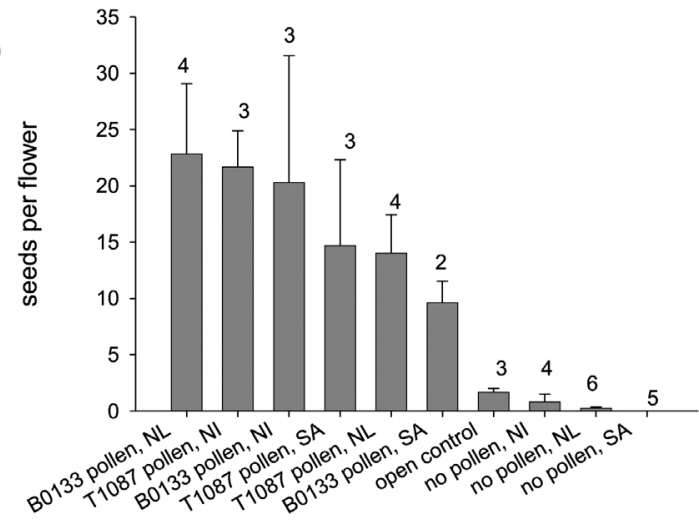

Figure 2. - Seeds per flower pollinated observed in Eucalyptus grandis maternal genotypes (a) B0133, (b) T1099 and (c) T1144, after performing AIP-controlled pollinations in combination with different methods of floral bud isolation. NI refers to non-isolation, NL to exclusion bag isolation and SA to sodium alginate isolation. Error bars represent standard error of the mean, with numbers above the error bars showing the number of replications per treatment. On average, each replicate consisted of three umbles, with seven flowers per umble.

tion achieving the highest seed yields in both T1099 $\mathrm{x}$ T1087 and T1099 x B0133 crosses (Figure 2b). For all three isolation treatments conducted on T1099, no seed was obtained when AIP was performed without manual application of pollen (Figure 2b). Genotype T1144 also displayed significant differences for seeds per flower pollinated $(\mathrm{F}=5.225 ; \mathrm{P}<0.001)$, with the non-pollinated sodium alginate isolation the only treatment not producing any seed (Figure 2c). In all three maternal genotypes, controlled pollination generally led to an increase in seed yields compared to natural pollination (open controls).

\section{Molecular marker analysis of pollen contamination}

Sodium alginate isolation was effective in excluding both self- and foreign-pollen from the stigma, and progeny derived from this isolation method were found to be $100 \%$ outcrossed with the applied pollen (Table 2). The exclusion bag, on the other hand, was not as effective, with the no-pollen treatment of seed parent B0133 being particularly contaminated with high amounts of selfpollen (67\% selfing). Non-isolated treatments had lower contamination than the exclusion bag treatments, although selfing was still evident (11\% selfing in the nopollen treatment of seed parent B0133). There was an unexpectedly high amount of selfing in the B0133 open control (45\%), compared to an absence of selfing in the T1144 open control (Table 2).

\section{Discussion}

Of the two CP-isolation methods tested here, sodium alginate isolation appears to be the most promising for application in eucalypt commercial controlled pollinations when using the AIP technique. Sodium alginate was effective in keeping external pollen away from the stigma, since no seed was produced in those treatments that were not manually pollinated but isolated in this way. In addition, flowers hand-pollinated and isolated with sodium alginate produced progeny that were $100 \%$ outcrossed with the applied pollen. The exclusion bag, on the other hand, was not as effective in protecting the stigma. Seed was produced in those treatments that were isolated with an exclusion bag without being handpollinated.

There is no doubt that the floral biology of eucalypts needs to be considered when developing a controlled pollination system (MoNCUR and BolAND, 2000). Although there is a time separation between pollen-shed and stigmatic receptivity in a single flower, it is still possible for a high degree of selfing to occur in the crown of a single tree. MORAN and BELL (1983) have predicted this to be in the region of $30 \%$ in natural eucalypt populations, but the present study suggests that the selfing rate in orchards can go as high as $45 \%$ (Table 2).

Prior deposition of self-pollen on the stigma may interfere with the flower's ability to use available crosspollen, resulting in reduced seed set (RAMSEY and Vaughton, 2000). Potential mechanisms of interference include clogging or blocking of stigma surfaces, stylar tissues or ovular micropyles and fertilising ovules that are later aborted due to late-acting self-incompatibility (SEAVEY and BAWA, 1986) or inbreeding depression (WASER and PRICE, 1991). In addition to late-acting SI, a previous study identified Eucalyptus grandis as also being cryptically self-incompatible (HORSLEY and JoHNSON, 2007). In species with cryptic SI, plants are able to set self-seed in the absence of competing crosspollen (BATEMAN, 1956). Thus to produce a useful CPsystem, it is evident that we need to develop methods to control selfing. Sodium alginate isolation appears to be useful in this regard, since there was no selfing in both 2005 and 2007 studies when using this method of isolation. 
Table 2. - Molecular marker analysis of pollen contamination in Eucalyptus grandis progeny created by the AIP method of controlled pollination in combination with different methods of flower isolation. A total of 20 progeny from each treatment were fingerprinted.

\begin{tabular}{lllccc}
\hline Isolation method & Maternal & Pollen & \multicolumn{3}{c}{ Contribution to progeny (\%) } \\
\cline { 4 - 6 } & parent & applied & $\begin{array}{c}\text { Applied } \\
\text { pollen }\end{array}$ & $\begin{array}{c}\text { Self } \\
\text { pollen }\end{array}$ & $\begin{array}{c}\text { Foreign } \\
\text { pollen }\end{array}$ \\
\hline sodium alginate & B0133 & T1074 & 100 & 0 & 0 \\
sodium alginate & T1144 & B0133 & 100 & 0 & 0 \\
sodium alginate & T1144 & T1087 & 100 & 0 & 0 \\
exclusion bag & B0133 & T1074 & 95 & 0 & 5 \\
exclusion bag & B0133 & none & $*$ & 67 & 33 \\
exclusion bag & T1144 & B0133 & 95 & 5 & 0 \\
exclusion bag & T1144 & T1087 & 100 & 0 & 0 \\
exclusion bag & T1144 & none & $*$ & 0 & 100 \\
non-isolated & B0133 & T1074 & 100 & 0 & 0 \\
non-isolated & B0133 & none & $*$ & 11 & 89 \\
non-isolated & T1144 & B0133 & 100 & 0 & 0 \\
non-isolated & T1144 & T1087 & 100 & 0 & 0 \\
non-isolated & T1144 & none & $*$ & 0 & 100 \\
OP control & B0133 & none & $*$ & 45 & 55 \\
OP control & T1144 & none & $*$ & 0 & 100 \\
\hline
\end{tabular}

* no pollen manually applied.

Eucalypts are largely insect-pollinated and successful pollinations are influenced by a number of factors, including diversity of flowering times, diversity in flowering intensity and number of pollen vectors present at flowering (ELDRIDGE et al., 1993). The lower fruit set of naturally pollinated flowers (open controls) in 2007 compared to 2005 could be attributed to limited insect activity in the orchard. The 2005 study was carried out during peak flowering and seed yields from the B0133 open control were relatively high (10.72 seeds per flower), which is suggested to be the result of high insect activity. On the other hand, the 2007 study was carried out at the end of the flowering season and this could have resulted in less insect pollinators being present in the orchard (due to low numbers of flowers). This is reflected in the seed yields obtained from genotypes T1099 and T1144 open controls ( 0.77 and 1.56 seeds per flower, respectively).

Differences in flowering intensity between the 2005 and 2007 studies could also explain the differences observed in selfing rate between B0133 and T1144 open controls (45 vs $0 \%$ ). In the 2005 study, individual trees had a higher flower density, which might have caused insect pollinators to remain within the canopy of the tree, thereby increasing selfing (SNOw et al., 1996). In contrast, trees had a lower volume of flowers in 2007 (being at the end of the flowering season) and there were also fewer trees flowering in the orchard, making insect pollinators travel further distances and more often between trees, and thereby increasing outcrossing
(GRIFFIN and OHMART, 1986; House, 1997). LeVRI (1998) noticed a similar effect of flowering intensity on selfing rate in Kalmia latifolia (Ericaceae). In that study, flowers receiving a mixed pollen load early in the flowering season exhibited a higher selfing rate, compared to flowers of the same age that received pollen later in the season (LEVRI, 1998).

Apart from physiological and biochemical factors, pollination is undoubtedly affected by weather conditions, such as wind and rain (ORTEGA et al., 2007), making isolation of the control-pollinated flower imperative under field conditions. The major effect of wind is that it increases self-pollination by vibrating the branches of the tree, causing pollen to fall from the anthers of flowers higher in the canopy onto the receptive stigmas of branches lower down (ELDRIDGE and GRIFFIN, 1983). Rain reduces or inhibits pollinator activity and delays flower opening and anther dehiscence (EIsIKOWITCH et al., 1991). With respect to controlled pollinations, rain could also wash pollen off the stigma (ORTEGA et al., 2007). All pollinations in the present study were carried out during summer, which in KwaZulu-Natal, South Africa, is rainy season, and thus could be a contributing factor to some of the low seed yields obtained. Genotype B0133 occurred in an orchard that consisted of more closely spaced trees than genotypes T1099 and T1144, and therefore B0133 may have been better shielded from rain and wind, giving rise to generally higher seed yields from both open- and control-pollinations. In addition to these environmental effects, the observed geno- 
typic differences could also be attributed to genetic based differences in reproductive success (CALLISTER, 2007; McGowen, 2007). Patterson et al. (2004) have shown that the proportion of capsules set following controlled pollination in $E$. globulus can range from $10-90 \%$ between female trees.

By reducing overlap between male and female reproductive functions, protandry is thought to reduce autogamous self-pollination (i.e. pollination of a flower by its own pollen) and self-pollen interference (BERTIN and NEWman, 1993). However, the $E$. grandis flowers in the present study were made artificially protogynous (stigma made receptive before anthesis) during the AIP method of controlled pollination, and were thus only partially effective in reducing within-flower selfing. This was confirmed by the high selfing (67\%) obtained in the no-pollen exclusion bag isolated treatment from maternal genotype B0133 (Table 2). Since the stigma is made receptive before the flower opens during AIP, contamination may occur just after flower opening, when the cut style is still receptive and self-pollen is at its maximum viability (Assis et al., 2005). It is therefore extremely important in the AIP method of controlled pollination that the isolation technique employed be highly efficient in excluding self-pollen.

\section{Conclusion}

From these results it is recommended that AIP-pollinated flowers be isolated to exclude foreign- and selfpollen when pollinations are performed under field conditions. Sodium alginate appears to be the isolation method of choice as, in addition to providing maximum protection to the stigma, it can be left on the tree to be disposed of by the ripening flower. Upon flower opening, the sodium alginate gel is shed naturally, increasing labour productivity as operators do not need to return to the tree to remove the isolation material, and hence reducing the cost of producing control-pollinated seed. The risk of physical damage to flower buds is also reduced when using sodium alginate isolation, as flowers are not exposed to the stresses resulting from a hot and humid atmosphere as they would be within the bag during exclusion bag isolation.

\section{Acknowledgements}

Many thanks to JACOB NGobese, Irene Moshoeshoe and Sipho MтнетнwA for their help with the controlled pollinations at the Shaw Research Centre. Thanks also to Dr. Alexander Myburg, Elna Cowley and Dr. Daleen VAN DYK at the University of Pretoria for the microsatellite marker analysis.

\section{References}

Assis, T., P. Warburton and C. Harwood (2005): Artificially induced protogyny: an advance in the controlled pollination of Eucalyptus. Australian Forestry 68: 27-33.

BARBOUR, L. (1997): Breeding better Blue Gums. Landscope 13: 37-41.
BARBour, E. L. and N. SPENCER (2000): The potential of a crossing technique for interspecific hybridisation between E. globulus and E. dunnii. In: Proceedings of QFRI/CRC-SPF symposium: hybrid breeding and genetics of forest trees. (Eds. H. S. Dungey, M. J. DiETERS and D. G. NikLES). Department of Primary Industries, Brisbane.

BAteman, A. J. (1956): Cryptic self-incompatibility in the wallflower: Cheiranthus cheiri L. Heredity 10: 257-261.

BERTIN, R. I. and C. M. NEWMAN (1993): Dichogamy in angiosperms. Botanical Review 59: 112-152.

BRADFORD, K. J. (2006). Methods to maintain genetic purity of seed stocks. University of California Division of Agriculture and Natural Resources Publication 8189. ANR Communication Services Web site, http:// anrcatalog.ucdavis.edu/pdf/8189.pdf.

Brondani, R. P. V., C. BRoNDANI, R. TARCHINI and D. GRATTAPAGLIA (1998): Development, characterisation and mapping of microsatellite markers in Eucalyptus grandis and E. urophylla. Theoretical and Applied Genetics 97: 816-827.

CAllister, A. (2007): Genetic selection reduces the cost of Eucalyptus globulus seed produced by mass supplementary pollination. In: Proceedings of IUFRO Working Group 2.08.03 - Eucalypts and diversity: balancing productivity and sustainability. Durban, South Africa, 22-26 October 2007.

Dutkowski, G. W., T. A. McRae, M. B. Powell, D. J. PilBEAM, J. Joyce, B. TIER and R. J. KerR (2006): Benefits from data and pedigree integration in genetic evaluation. In: Breeding for success: diversity in action. $13^{\text {th }}$ Australasian Tree Breeding Conference. 18-21 April 2006. Christchurch, New Zealand.

Eisikowitch, D., Z. GAT, O. KARNI, F. CHECHIK and D. RAZ (1991): Almond blooming under adverse conditions. A compromise between various forces. In: Proceedings of Plant-Animal Interaction in Mediterranean Type Ecosystems. Crete, Greece, Medecos VI. pp. 243-240.

EldRIDGe, K. G. and A. R. GRIFFIN (1983): Selfing effects in Eucalyptus regnans. Silvae Genetica 32: 216-221.

EldRIDGE, K., J. DAvidson, C. HARWOOD and G. vAN WyK (1993): Eucalypt domestication and breeding. Oxford University Press, New York.

Griffin, A. R. and C. P. OHMART (1986): Pollination ecology of Eucalyptus, Biennial Report 1983-1985. CSIRO Division of Forest Research, Canberra. pp. 26-28.

Groom, M. J. (1998): Allee effects limit population viability of an annual plant. American Naturalist 151: 487-496.

HaRbard, J. L., A. R. GRIFFIn and J. EspeJo (1999): Mass controlled pollination of Eucalyptus globulus: a practical reality. Canadian Journal of Forest Research 29: 1457-1463.

Harbard, J. L., R. Griffin, J. E. Espejo, C. Centurion and J. RUSSELL (2000): 'One stop pollination' a new technology developed by Shell Forestry technology unit. In: Proceedings of QFRI/CRC-SPF symposium: hybrid breeding and genetics of forest trees. (Eds. H. S. Dungey, M. J. Dieters and D. G. NikLes). Department of Primary Industries, Brisbane. pp. 430-434.

Horsley, T. N. and S. D. Johnson (2007): Is Eucalyptus cryptically self-incompatible? Annals of Botany 100: 1373-1378.

Horsley, T. N., S. D. Johnson and T. K. Stanger (2007): Optimising storage and in vitro germination of Eucalyptus pollen. Australian Journal of Botany 55: 83-89. 
Horsley, T., S. Johnson and A. MyburG (2008): Factors affecting reproductive success in Eucalyptus. Sappi Research Document 01/2008, Sappi Forests, South Africa.

House, S. M. (1997): Reproductive biology of eucalypts, pp. 30-55. In: Eucalypt ecology: individuals to ecosystems, edited by J. E. WILLIAMS and J. C. Z. WoINARSKI, Cambridge University Press, Cambridge.

Lehtila, K. and K. Syruanen (1995): Positive effects of pollination on subsequent size, reproduction, and survival of Primula veris. Ecology 76: 1084-1098.

LEVRI, M. A. (1998): The effect of timing of pollination on the mating system and fitness of Kalmia latifolia (Ericaceae). American Journal of Botany 85: 1626-1630.

McGowAN, M. H. (2007): Genetic control of reproductive traits in Eucalyptus globulus. PhD thesis, University of Tasmania.

Moncur, M. W. (1995): Techniques for pollinating eucalypts. Australian Centre for International Agricultural Research, Canberra. pp. 1-19.

Moncur, M. W. and D. J. Boland (2000): Production of improved Eucalyptus nitens seed for reforestation. Australian Forestry 63: 211-217.

Moran, G. F. and J. C. Bell (1983): Eucalyptus, pp. 423-441. In: Isozymes in Plant Genetics and Breeding. Part B., edited by S. D. TANKsley and T. J. OrTon, Elsevier, Amsterdam.

Ortega, E., F. Dicenta and J. Egea (2007): Rain effect on pollen-stigma adhesion and fertilisation in almond. Scientia Horticulturae 112: 345-348.

Patterson, B., R. E. Vaillancourt, D. J. Pilbeam and B. M. PotTs (2004): Factors affecting outcrossing rates in Eucalyptus globulus. Australian Journal of Botany 52: 773-780.

Potts, B. M. and J. B. MARsDen-Smedley (1989): In vitro germination of Eucalyptus pollen: response to variation in boric acid and sucrose. Australian Journal of Botany 37: 429-441.

Pound, L. M., M. A. B. Wallwork, B. M. PotTs and M. SEDGLEY (2003): Pollen tube growth and early ovule development following self- and cross-pollination in Eucalyptus nitens. Sexual Plant Reproduction 16: 59-69.

Pound, L. M., M. A. B. Wallwork, B. M. Potts and M. SEDGLEY (2002): Early ovule development following self- and cross-pollinations in Eucalyptus globulus Labill. ssp. globulus. Annals of Botany 89: 613-620.

RAMSEy, M. and G. VAughton (2000): Pollen quality limits seed set in Burchardia umbellata (Colchicaceae). American Journal of Botany 87: 845-852.

SEAVEY, S. R. and K. S. BAWA (1986): Late-acting selfincompatibility in Angiosperms. Botanical Review 52: 195-219.

Snow, A. A., T. P. SpIRA, R. Simpson and R. A. KLIPS (1996): The ecology of geitonogamous pollination, pp. 191-216. In: Floral biology, edited by D. G. LLOYD and S. C. H. BARRETT, Chapman and Hall, New York.

Sundstrom, F. J., J. Williams, A. VAn Deynze and K. J. BRADFORD (2002): Identity preservation of agricultural commodities. University of California Division of Agriculture and Natural Resources Publication 8077. ANR Communication Services Web site, http://anrcatalog.ucdavis.edu/pdf/8077.pdf.

VAN WYK, G. (1977): Pollen handling, controlled pollination and grafting of Eucalyptus grandis. South African Forestry Journal 101: 47-53.

WASER, N. M. and M. V. PRICE (1983): Optimal and actual outcrossing, and the nature of plant-pollinator interaction, pp. 341-359. In: Handbook of experimental pollination biology, edited by C. E. JONES and R. J. LITTLE, Van Nostrand Reinhold, New York.

WASER, N. M. and M. V. PRICE (1991): Reproductive costs of self-pollination in Ipomopsis aggregata (Polemoniaceae): are ovules usurped? American Journal of Botany 78: 1036-1043.

Williams, D. R., B. M. PotTs and P. G. Black (1999): Testing single visit pollination procedures for Eucalyptus globulus and E. nitens. Australian Forestry 62: 346-352.

Appendix A. - Mating design showing number of Eucalyptus grandis flowers pollinated per treatment.

\begin{tabular}{lccc}
\hline \multirow{2}{*}{ CROSS } & \multicolumn{3}{c}{ ISOLATION TREATMENT } \\
\cline { 2 - 4 } & None & Exclusion bag & Sodium alginate \\
\hline B0133 x T1074 & 102 & 106 & 110 \\
B0133 x no pollen & 116 & 102 & $*$ \\
T1099 x B0133 & 50 & 41 & 42 \\
T1099 x T1087 & 40 & 39 & 43 \\
T1099 x no pollen & 81 & 95 & 73 \\
T1144 x B0133 & 50 & 45 & 47 \\
T1144 x T1087 & 42 & 50 & 48 \\
T1144 x no pollen & 80 & 91 & 78 \\
\hline
\end{tabular}

* treatment not included. 